\title{
Identidades en tensión: devenir de una etno y gastropolítica en Isla de Pascua ${ }^{1}$
}

\author{
Sonia Montecino Aguirre $\left(^{*}\right)$ \\ Rolf Foerster González( $\left.{ }^{* *}\right)$
}

\begin{abstract}
RESUMEN
Este artículo aborda el devenir de la etnopolítica rapanui tocando una de sus facetas menos conocidas, la de la alimentación y la cocina en tanto sistema de símbolos, técnicas y productos que operan en la negociación de las identidades y en la impugnación al orden colonial. Un análisis histórico-antropológico pone de manifiesto que la gastropolítica funciona en Isla de Pascua como un espacio donde política, cultura y reproducción se anudan para la creación y recreación permanente de un espacio en el cual la comunidad se expresa y pacta sus relaciones intra e interéticas.
\end{abstract}

Palabras clave:

Cocina - política - identidades.

(*) Doctora en Antropología de la Universidad de Leiden. Profesora titular de la Universidad de Chile.

(*) Doctor en Antropología de la Universidad de Leiden. Profesor asociado de la Universidad de Chile.

Artículo enviado el 26 de enero de 2012. Aceptado por el Comité Editorial el 14 de mayo de 2012.

Correo electrónico: soniamaguirre@yahoo.es rolf22@gmail.com

${ }^{1}$ Este artículo forma parte de la investigación Fondecyt $N^{\circ} 11101109$ que realizan los autores. 


\begin{abstract}
This article discusses the future of rapanui ethnopolitics, playing one of their lesserknown facets, the food and cooking as a system of symbols, techniques and products that operate in the negotiation of identities and in the confrontation of colonial order. A historical-anthropological analysis shows that gastropolitics operate on Easter Island as a place where politics, culture and reproduction are tied on the ongoing creation and recreation of space in which the community expresses and pacts their relationships within and inter-etics.
\end{abstract}

Keywords:

Cooking - politics - identities.

La centralidad del alimento en las distintas aristas del devenir rapanui, es un elemento que salta a la vista desde la observación directa y desde los datos bibliográficos y documentales. Sin duda más allá o más acá de las consideraciones productivas, la situación insular fue y es un factor relevante para el particular despliegue de su discurso culinario. Asimismo, su pertenencia al universo polinésico ${ }^{2}$ emerge como memoria en la cual los intercambios alimenticios y las ceremonias colectivas poseen una dimensión política al ser parte de la verificación del prestigio de los linajes o de las familias ${ }^{3}$ y también un medio de intercambio; pero sobre todo los distintos avatares de la colonización y anexión al territorio chileno marcarán la impronta de una gastropolítica que se entrevera de manera singular con la etnopolítica presente en los vínculos de la comunidad pascuense con la Compañía Explotadora de Isla de Pascua, el Estado y segmentos de la sociedad chilena.

Si bien la noción de gastropolítica (Appadurai, 1981) no ha sido utilizada en los análisis de los nexos políticos interétnicos en Isla de Pascua, a excepción de las investigaciones ligadas a antropología de la alimentación ${ }^{4}$, puede sernos útil para comprender los conflictos de intereses, las resistencias locales, las negociaciones y las tensiones simbólicas y económicas que se expresan en los procesos identitarios que fijan en lo culinario un operador y un lenguaje de las diferencias. Appadurai entiende la gastropolítica como un proceso en el cual el alimento es al mismo tiempo el medio y el mensaje de un conflicto. Weinsmantel (1994), por ejemplo, muestra cómo las

\footnotetext{
${ }^{2}$ Rapanui forma parte del llamado "triángulo polinésico" compuesto por Hawaii, Nueva Zelanda e Isla de Pascua. Dice McCall (1998): "Los rapanui se desarrollaron sobre el patrón polinesio básico que trajeron consigo, el cual era parte de su equipo de sobrevivencia cultural, tanto como el punzón, el hacha, el ñame o un brote de taro. En la actualidad... las ideas no son importadas de los polinesios, sino mayormente por los extranjeros. Pero el intercambio entre los sistemas extranjeros y domésticos permanece, y ya sea que estas ideas vengan desde las Marquesas prehistóricas o del Chile contemporáneo, toman su lugar en y deben acomodarse al ambiente de Rapanui. Rapanui, entonces es diferente del resto de la Polinesia por su extremado aislamiento, pero está relacionada con sus hermanas islas por virtud de su historia compartida y su herencia común" (Op.cit, p. 3). Estos legados polinésicos se remontan a poblaciones que, de acuerdo al mismo McCall, vivieron en alguna parte del sur de China y migraron en cuatro oleadas, la primera pasando por Filipinas hasta Nueva Caledonia. La segunda hacia Fiji y algunos lugares de Micronesia. En el 1300 a.C. los primeros polinesios llegaron a Tonga, dejando sus vestigios en Samoa y en ciertas partes de las Islas Cook. La tercera oleada, en el 500 d.C. se expandió hacia las Marquesas pasando por Hawaii en el norte y las Islas Cook por el sur, colonizando Isla de Pascua. La cuarta oleada alcanzó las lejanas tierras de Nueva Zelanda.

${ }^{3}$ Como se aprecia en Bataille-Bengugui (1996).

${ }^{4}$ Cf. Montecino, 2009.
} 
desigualdades de género pueden leerse desde esa perspectiva:

“...a pesar de esta aparente impotencia, es considerable el potencial para la "gastropolítica" que se proporciona a quienes controlan las comidas. Las estructuras formales de la cocina y la etiqueta en Zumbagua proporcionan instrumentos delicados para la comunicación de mensajes sobre la posición social y el poder relativo, e incluso crean oportunidades para reajustar el statu quo. Lejos de ser un espejo inalterable de la estructura familiar, este "símbolo de la subordinación femenina" da a la mujer que maneja el cucharón la oportunidad de pronunciar graves insultos mientras proclama humildemente su absoluta falta de poder político" (p. 44).

Utilizaremos, en este artículo, ese concepto para mostrar una posible relectura de la etnopolítica isleña y de los modos en que la cocina ${ }^{5}$ se convierte en mensaje y negociación de intereses en las tensiones políticas tanto del pasado como de la actualidad.

\section{Alimentos, reciprocidad y política. El discurso mítico e histórico del umu}

El umu -la cocción al vapor en un horno de tierra- ha caracterizado y dominado las técnicas culinarias pascuenses. Los productos que en él se convierten en alimentos, así como su tecnología son entendidos como una herencia del fundador Hotu Matu a quien venido de Hiva, un sitio descrito como "tierra de abundante comida"6, viaja hacia la isla forzado por el hundimiento paulatino de su tierra en el mar, y legitimado por la visión (o sueño) del iria'tua Hau Maka, cuyo espíritu visitó Rapa Nui. La tradición oral habla de una primera expedición de siete hombres que arribó a la isla antes que el fundador:

\footnotetext{
"Vinieron y atracaron en Hanga Tepau (Playa de Vinapú); dejaron la nave en Hanga Tepau...Cuando habían llegado a tierra, se quedaron (algún tiempo) e hicieron plantaciones de ñames; Ku'uku'u hizo las plantaciones... Sintieron hambre; se lanzaron todos mar adentro. Trajeron los peces a la playa con su cuerpo no más; hubo abundancia de peces en la playa...Ira y Raparenga vieron que no había fuego para hacer curanto. Enviaron a dos hombres, quedándose cinco, a la nave a buscar fuego. Estos llegaron, sacaron el fuego y volvieron, llevando fuego a Hanga Hoonu. Trajeron los peces y los colocaron encima de las piedras, trajeron leña de mako' ${ }^{7}{ }^{7}$, encendieron el fuego y cocieron (los peces); comieron los siete juntos" (Englert, 2007, pp. 37-39, acá y en adelante los subrayados son nuestros).
}

\footnotetext{
${ }^{5}$ Entendida como un entramado de productos, técnicas (recetas) y símbolos que producen identidades sociales familiares, locales y nacionales.

${ }^{6}$ Cf. Englert, 2007, p. 51.

7 Mako'i: "Frutos muy pequeños// árbol cuya madera rojiza es usada frecuentemente en la artesanía. Thespesia populnea//s. frutos del miro tahiti" (Diccionario Práctico Rapanui-Castellano, p. 82).
} 
Resaltan dos elementos ligados a una ingesta de larga data: los ñames y los peces, así como dos técnicas: el tunuahe ${ }^{8}$ (cocido sobre las piedras calientes) y el uти o "curanto" tubérculos, el barco de Hotu Matu'a también los trajo. Teke había robado 18 clases de ñame a Ma'eha, los cuales partieron en la travesía, pero también "robó" sus nombres que memorizó uno a uno. Teke quedó como depositario de los saberes (y poderes -mana-) que el nominar correctamente trae consigo'.

Métraux (1950), informa del momento fundacional: "Aquel mismo día todos los que habían venido en las canoas desembarcaron. Descargaron las plantas y los animales que llevaban con ellos. Esas plantas eran taros, ñames, cañas de azúcar, plátanos, el ti y luego, todos los árboles que han desaparecido: las majaguas, los toro-miro. En cuanto a los animales, sólo habían sobrevivido las gallinas y las ratas. Hotumatua había llevado varias otras especies, pero no llegaron hasta más tarde, con los blancos" ( pp. 203-204).

Por su lado, Felbermayer (1948) recopila de Horacio Teao esta versión:

“Embarcaron también Camotes, Taro, Uhi, Caña de Azúcar, Plátanos, el Toromiro, el Mahute, el Ngaoho, gallinas y demás herramientas... Al segundo día de su llegada La Reina dio a luz su primer hijo a quien llamaron Tuuma-Heke. Los recién llegados trabajaron y cultivaron los campos, sembrando las semillas traídas; durante los primeros cinco meses se alimentaron sólo de pescado, tortugas, mariscos hasta que la tierra empezó a producir y dar las primeras cosechas" ${ }^{\prime 10}$.

Así de Hiva proviene el ya mencionado ñame (uhi), los camotes (kumara) y el taro. Por otro lado, la caña de azúcar (toa) y el ti (Cordyline terminalis). Entre las frutas, el plátano (maika) y del reino animal, las gallinas (moa), el ratón, los peces (ika), los mariscos y las tortugas. También la leña para calentar las piedras y cocinar en umu. La tríada de tubérculos, carnes y frutas compondrá la dieta de los antiguos rapunui escribiendo una sintaxis con un sentido culinario de densas connotaciones. Esta tríada se activa en el umu que la reúne en su oquedad aliente para convertirla, ya cocinada, en medio de intercambio fundamental entre grupos, familias y sujetos. El primer rasgo de la gastropolítica rapanui se construye en el imaginario mítico de una identidad culinaria transmitida trasngeneracionalmente y en el papel que la propia tradición oral otorga al intercambio de comida cocida.

\footnotetext{
${ }^{8}$ Tunu'ahi: "Cocer al fuego, asar.// s. Asado al fuego" (Diccionario Práctico Rapanui-Castellano, p. 153).

${ }^{9}$ Umu: "Curanto//s. comida preparada en curanto/ / Cocina (habitación)/ / s. Cocina (aparato o similar)" y 'Umu pae: "s. Pequeña construcción que se trata de un hoyo en la tierra en el que se preparaba la comida. Su característica es que está rodeado de unas piedras de mediano tamaño a manera de pequeñas paredes" (Diccionario Práctico Rapanui-Castellano: 156). Englert (1974) nos dice: Umu: "cocimiento de alimentos en la tierra con piedras previamente calentadas, lo que en Chile se llama "curanto" (voz derivada del idioma mapuche); el mismo hoyo en que se hace la comida; umu pae, hoyo permanente cercado de piedras; umu pae pae, curanto estable con un cobertizo de paja para resguardarlo de la lluvia y el viento; umu keri okaoka, hoyo que en cualquier parte se hace cavando la tierra, sin cerco de piedras..." ( p. 359).

${ }^{10}$ El conocimiento de las propiedades de ciertos vegetales, como sugiere la tesis de Valentina Fajreldin (2004), en la actualidad, muestra un sinuoso sistema de saber-poder, como en el uso de la planta Matu'a Pua'a por tres nuas (mujeres mayores y casadas) respetadas por la comunidad pues poseen mana o "poder" para prepararlo. "...el Mana es el que actúa más que la mera coincidencia "química". El mana presente en la planta misma, ligada al volcán y a su origen legendario ancestral, y/o el mana presente en el especialista, depositario de la confianza ancestral" (pp. 175 - 176).
} 
Asimismo, el discurso mítico especifica, en el origen de los moai, un culto a los antepasados signado por el poder masculino: la imagen fálica -y especialmente del balano del pene- delata el poder ligado a ese género, por medio de un mensaje pétreo repetido incansable y espectacularmente. Ello se devela en la narración El Origen de los Moai, así como los indicios de los múltiples significados del umu. Dos jóvenes escultores no quedan conformes con el moai que han hecho pues no tenía cuello. El Rey Miro envió a un grupo de jóvenes a preguntar a Kave Heke la clave para concluir la escultura. El sabio los alimentó, pero cuando le interrogaron, no respondió. Por tres días los jóvenes escultores comieron curanto, pero no tuvieron respuesta a sus preguntas. Deciden regresar, pero Kave Heke, les cocina un nuevo uти tao "el cual abrió al amanecer, y les ofreció de comer, una vez comidos, les despidió..." (Huke, 1995, p. 49). Cuando partían, les habló de manera oracular: "Abajo en vosotros está el moai" (Ibíd.). En el camino, uno de ellos orinó y se vio el pene: era la clave dada por Kave Heke. Solo debían tallar lo que portaban en su propio cuerpo.

Resalta, por un lado, la hospitalidad de quien recibe con alimentos, con un umu tao o uти tahu, definido por Englert como "curanto diario para trabajadores que vienen a trabajar" (Op. cit., p. 359). Se trata de un umu tahu de Kave Heke para los escultores, con la idea de pago y reciprocidad por su trabajo. Por el otro, la gastropolítica rapanui: no se puede rehusar el alimento de quien lo dona sin romper la sociabilidad. El tercer nudo lo constituye el $u m u$, en tanto operación culinaria que funciona como gozne de la congregación ${ }^{11}$.

Recordemos que también la cocina, ahora como trabajo femenino, gravitará -según la tradición oral- en la fabricación de los moai y en su fin:

\begin{abstract}
"Había una vieja para hacer el curanto para los trabajadores de los moai, eran muchos estos trabajadores. Día tras día preparaba esa vieja cocinera el curanto para los escultores. Cierto día no llegó la vieja cocinera con su gente. Los hombres abrieron el curanto que era de langosta y comieron. Al llegar después ella, vio que el curanto había sido abierto y que no sobraba langosta; los hombres habían comido todo y acabado con la comida. No dieron de comer a la vieja. Ella lloró y gritó hacia los moais: ¡Muchachos, con todo vuestro peso, caed al suelo! Cayeron los moai" (Englert 2007, p. 93).
\end{abstract}

Ambos relatos exponen dos aristas de la gastropolítica isleña: la mencionada comida cocinada como "pago", como "moneda" vicaria del intercambio; y por el otro, la transgresión (el egoísmo de los escultores) de la cadena de dones y contra dones que supone la reproducción social. El correlato de género expresa una división sexual del trabajo: cocina/femenino; escultura/masculino. En la primera asociación umufemenino: oquedad (vientre) interior de la tierra que, unido a las piedras calientes, permite alimentar y pagar a los vivos por su trabajo; en la segunda, las piedras erigidas afuera (los penes), hacia el cielo, como tributo a los muertos que hacen posible la existencia de los vivos.

Otras facetas del umu como operador político se esbozan en la vida precolonial rapanui. Los intercambios entre los dos clanes principales que poblaban la isla,

\footnotetext{
${ }^{11}$ En este caso, de los jóvenes y el sabio que se los ofrece.
} 
$t u^{\prime} u$ aro y $t u^{\prime}$ hotuiti se expresaron en los matrimonios ${ }^{12}$, en los recursos alimenticios controlados por cada uno de ellos y en las ocasiones festivas. En estas como dice McCall, "Honrar a los muertos es un método excelente para que los vivos alardeen públicamente sobre sus propios logros" (Op.cit., p. 19). Las fiestas que se celebraban luego de los conflictos, llamadas Koro ${ }^{13}$, según Métraux (1950) implicaban un sistema de invitaciones en el que se devolvía a quienes habían sido antes anfitriones. Por su lado, las paina ${ }^{14}$ recordaban a un pariente fallecido hacía unos años, y los areuti, suponían la construcción de una cabaña en la cual las y los jóvenes danzaban y cantaban. Los koro se preparaban:

“...con años de antelación y se esforzaba para que su corral pudiera ofrecer 200 o 300 aves. Sus hermanos o primos lo ayudaban, habitualmente, aportando partes proporcionales. Luego, el organizador tenía que doblar la superficie de sus cultivos para conseguir lo necesario para agasajar a sus invitados. El día de la fiesta, los alimentos se apilaban sobre andamiajes y las aves de corral eran atadas en grupos de diez ante la multitud de invitados. El hijo se acercaba al padre y le entregaba ceremoniosamente un pollo. El padre lo tomaba y lo pasaba enseguida a uno de sus parientes. Luego se acercaba a la larga fila de aves y las repartía entre los parientes. Las aves que quedaban después de esas liberalidades eran entregadas al hermano del héroe de la fiesta y ese hermano las llevaba simbólicamente sobre la espalda" (Métraux, p. 174).

El homenajeado regalaba sus aves a su mujer quien las traspasaba a su hermano y éste a otro: para consumirlas debían haber circulado por cinco manos. El organizador podía, asimismo, recibir pollos -en una cadena inversa- de algún pariente que había asistido a otra fiesta. El festejado debía, asimismo, brindar tubérculos y carne cocidos en el umu a quienes les habían ofrecido el koro (Cf. Métraux, pp. 174-175).

Es interesante notar que la cría de aves de corral fue para los antiguos rapanui una fuente proteica, y un modo de sellar los pactos de sociabilidad, un símbolo de la comunidad como lo atestiguan las fiestas de koro. El paina pone en escena, las "deudas" que siguen vigentes y que se pagan desde los vivos a los muertos y de estos a los vivos, en un circuito infinito. El muerto es honrado por lo que dio y por lo que dará, y a la vez se "encarna" en el hijo que reitera el gesto. Así la comida (los pollos) es signo de las contraprestaciones y funciona como bisagra que conecta a las familias, incluyendo a los parientes vivos y difuntos. Toda la comunidad se activa en la fiesta y hace funcionar una cierta economía política del orden social. Otro visaje de la gastropolítica rapanui: el control -poder sobre y de los alimentos (vicariamente representados en el $u m u$ )- no debe concentrarse en una persona o familia, sino que debe circular para producir su flujo constante beneficiando a toda la colectividad.

\footnotetext{
${ }^{12}$ Dentro de un orden patrilocal y patrilineal, la primogenitura era la expresión de la posesión de las tierras y objetos del padre. Se practicó la exogamia, es decir, las mujeres se casaban con hombres provenientes de un clan distinto al natal. Pero, también los hermanos menores del primogénito debían salir a otro sitio para casarse y reproducir su existencia (Cf. McCall, Op.cit., p. 20).

${ }^{13}$ Métraux (1940) define el término como "padre" y relacionado a las fiestas en honor de un padre o una madre; el Diccionario Práctico Rapanui-Castellano lo define como, "padre.// Tío (en cualquier grado.// s. Hombre mayor//s. Fiesta, celebración" (75); Fuentes (1960) lo traduce también como fiesta/padre.

${ }^{14}$ Paina: "Caseta de madera que se ponía en un anda, especialmente construida para la celebración llamada koro paina. / trad. Se usaba para llevar al moderador de la celebración" (Diccionario Práctico Rapanui- Castellano, p. 109).
} 
La bibliografía sobre Isla de Pascua coincide en que las variadas festividades de los antiguos pascuenses fueron expresión de la oposición rivalidad/reciprocidad. Además de las asociadas al ciclo de vida de las personas (nacimiento, casamiento, muerte), los koro ya citadas se unieron a otras como los koro ate atua, definida por Campbell (1971) como: "una fiesta con cantos y comidas en honor a algún personaje importante, o de un acontecimiento digno de ser recordado, como la llegada de los primeros barcos europeos u otros sucesos..." (p.95). En todas estas ocasiones las comidas colectivas fueron centrales. Campbell las denomina "umu pare-haonga". Pare ha'onga es definido como "Curanto, a manera de salario, entregado a quien está a cargo de construcciones o de la composición"15 y por Englert (1974) como umu parehaona: "Curanto que se hace al preparar o inaugurar un trabajo o una fiesta" (p. 359).

Esos rituales, cuyos sentido político fue amortiguar la guerra y los conflictos interclánicos, sitúan al umu como signo de la reciprocidad en tanto norma, pero sobre todo lo convierten en "bien" social para ejercerla, al transformar los productos en "moneda" y símbolo del intercambio. Por ello, las fiestas sin banquete no tendrían esa relevancia que adquirieron, ya sea como incorporación colectiva de los alimentos a través del consumo ritual o bien para que algunos miembros de la comunidad ostentaran su poder y echaran a rodar el juego rivalidad/reciprocidad. Sin embargo, al mismo tiempo construyeron el valor del comensalismo: la comunidad se hermana en la ingesta, establece nexos de parentalidad, supera la violencia, "sacrifica" en colectivo los bienes (los alimentos) a través del trabajo culinario y de su consumo. Este gesto político complejo funciona simultáneamente como negación de la acumulación del recurso alimento, pero también como espacio de restitución de diferencias que deben ser zanjadas permanentemente.

Por último, hay otra fiesta asociada a la transformación vivida por la sociedad pascuense: del culto a los moais al del hombre pájaro. En ese tránsito, al parecer, emerge el huevo como emblema de poder. Surge así un ritual cuyo objeto era "...la caza de los suculentos huevos"16 que daba primacía en la jefatura a un clan u a otro durante un año. Estos nuevos "reyes" (tangata manu u "hombres pájaros") fueron elegidos en una gran celebración en Orongo, a los pies del volcán Rano Kau. McCall informa que para este ceremonial político se preparaban "...haciendo acopio de cuanta comida tuvieran" (Op.cit., p. 25), surgiendo una división sexual del trabajo en base a la oposición mujeres, cocina crianza de los hijos / hombres tallado y tatuaje. Toda la sociedad se congregaba a esperar el designio del Dios Make Make: el mata to'a (guerrero) que ganaba la competencia -a través de un hopu (servidor) que era enviado al islote donde anidaba el manutara (Sterna lunata) y retornaba con su huevo- sería el nuevo "Rey".

Métraux (1950) señala que en las juntas de Mataveri para celebrar la presencia del nuevo "hombre pájaro":

\footnotetext{
${ }^{15}$ Diccionario Práctico Rapanui-Castellano, p. 113.

${ }^{16}$ La frase es de McCall y se podría conjeturar que parte de las energías violentas del canibalismo, como se apreciará en la cita de más adelante, se sublimaron en este ritual, a pesar que ello no implicó el cese de las hostilidades entre los grupos rivales, sino una suerte de frágil equilibrio anual.
} 


\begin{abstract}
"Se sacrificaban a Make Make víctimas humanas designadas por el sacerdote o por el hombre pájaro. Los cuerpos de esas víctimas cocinados en enormes hornos subterráneos, eran servidos en ruidosos banquetes ininterrumpidos por danzas y salmodias. Parientes y amigos del Elegido, ebrios de triunfo, lanzaban burlas a rivales o adversarios...El huevo de manutara, vaciado y rellenado de tapa ${ }^{17}$, colgaba en la cabaña del hombrepájaro. Era contemplado con veneración por las grandes virtudes mágicas que se le atribuían. Se suponía que aportaba la abundancia. 'El huevo era un mago', me explicó Tepano: 'daba batatas, pollos, pescado, anguilas, langostas'. La pesca en altamar empezaba justo después de su descubrimiento" (Op.cit., pp. 138 - 139).
\end{abstract}

La ceremonia de Orongo supuso diversos consumos. Primero, el de la comida cotidiana en el sitio de la fiesta; segundo un banquete, y por último una ingesta caníbal en honor a Make Make. La reciprocidad se vacía hacia este Dios que propicia al nuevo "rey" y su ofrenda es consumida bajo la técnica del umu. Por otro lado, simbólicamente el huevoun útero de fertilidad- aporta los alimentos caros a la dieta (tubérculos, peces y aves de corral) y es la metáfora de la abundancia del reinado del nuevo jefe.

Así, el plano mítico y el festivo nos reenvían al cuidado obsesivo de las retribuciones. Cada ave alimentada, cada tubérculo cosechado, cada fruta es preciosa porque arranca su origen en el fundador (antepasado) y porque implica el trabajo colectivo dentro de un medio ambiente poco fértil y bajo un control de recursos limitado por clanes territorializados. Por eso, la fiesta es el modo de zanjar los litigios del poder y es la expresión viva de la gastropolítica como modo de negociar treguas en la violencia, de hacer comparecer las deudas con los muertos, de escenificar una y otra vez la necesaria circulación del alimento a través del umu que los convierte en "moneda" vicaria del pago. De este modo, cocina $(u m u)$, poder y colectividad constituyen la triple faz esculpida por los antiguos rapanui, dotando de espesor histórico, mítico y político el entramado de sus relaciones sociales, verificado de manera constante en el peso que la fiesta y el banquete tuvieron en los procesos de guerra y paz.

\title{
La gastropolítica en tiempos de colonización: la guerra culinaria de Angata
}

Isla de Pascua fue descubierta por la expedición holandesa de Roggeween en 1722, visitada posteriormente por los hispanos a cargo de Felipe González de Haedo en 1770, por el capitán James Cook en 1774 y por el conde de La Pérouse en 1786. En todos estos "avistamientos" y contactos de primera mano en el siglo XVIII, quedó de manifiesto que los recursos alimentarios fueron objeto de una disputa y negociación permanente, que van desde la entrega subordinada (holandeses), a un intercambio recíproco (ingleses) o de donaciones "gratuitas" por parte de españoles y franceses.

La relación anónima del viaje de Roggeween informa:

"Después que los habitantes de Isla de Pascua hicieron prueba de la potencia de nuestras armas, como ya hemos relatado, comenzaron a tratarnos de una manera más cortés, y nos trajeron de sus chozas todo tipo de vegetales, cañas de azúcar, con ñames, plátanos, y una gran cantidad de aves de corral, las que vinieron muy oportunas, y se dedicaron a refrescarnos enormemente".

\footnotetext{
17 "Especie de género hecho con corteza de árboles" (Diccionario Práctico Rapanui- Castellano, p.140).
} 
Carl F. Behrens señala en su diario que los alimentos se entregaron para recuperar los cuerpos de aquellos que fueron asesinados por los europeos:

“Estas buenas gentes, para tener [avoir] los cuerpos muertos nos dieron nuevamente toda clase de víveres. Su consternación era, por lo demás, muy grande, gritaban y se lamentaban de manera lúgubre. Todos, hombres, mujeres y niños pasando delante de nosotros portaban ramas de palma y una especie de estandarte rojo y blanco [une esce d'étendart rouge \& blanc]. Sus presentes consistían en higos de India, nueces, cañas de azúcar, pollos y raíces. Luego se arrodillaron, plantaron sus banderas [drapeaux] y nos presentaron sus ramas de palma en señal de paz".

Con los españoles las cosas cambiaron, su llegada a Pascua desde el puerto del Callao, tenía como intención no sólo reafirmar la soberanía de España en esos dominios (en disputa entre ingleses y franceses), sino también establecer una futura colonia, así se entiende el cuidado en las relaciones con la población y en el intercambio:

“...vinieron nadando tres hombres de estos naturales, pintados de distintos colores, manteniéndose cerca del bote, con muchos gritos, hasta que el uno de ellos, se acercó tanto que me regaló un pedazo de ñame. Le di biscocho y tabaco, todo recibió: su comida traía en una taleguita hecha de paja fina bien tejida" (en Mellén).

La expedición española, con alimentación en sus bodegas para varios meses, no requería de los recursos pascuenses, por ello ponen el acento en la reciprocidad: "Los tratamos con todo cariño, y les regalamos cuanto nos piden".

Radicalmente distinta fue la llegada de Cook. Su necesidad de alimentos frescos y de agua era urgente. Tenía esperanzas de encontrar en Pascua un edén (era la imagen que se tenía por la relación de Behrens) y arribó a una ínsula donde la comunidad poco tenía para ofrecerle e intercambiar. No obstante, Cook negoció día a día con la comunidad, empero no fue:

“...muy afortunado comerciando con la gente. Parecían ser efectivamente tan indigentes que no tenían ninguna provisión de sobra. Unas pocas cestas apelmazadas llenas de batatas, algunas cañas de azúcar, racimos de bananas y dos o tres pequeñas aves ya preparadas, fueron la toda compra que habíamos hecho por algunas herramientas de hierro y unas telas de Tahiti" (relación de George Forster).

Y su fortuna con las aguas:

“...tampoco encontraron ni el menor indicio de agua dulce, pues lo que los indígenas les trajeron fue realmente agua salada" (relación de Cook).

Es muy probable que los isleños "escondieran" deliberadamente sus alimentos y sus recursos de agua a los extranjeros, así como evitaban que vieran a la casi totalidad de sus mujeres y niños ${ }^{18}$, con el propósito evidente de evitar lo vivido en 1722 (los

\footnotetext{
${ }^{18}$ Cook dice: "El número de habitantes de estas islas parecía no exceder de seiscientos o setecientos, y más de los dos terceras partes de los que vimos eran varones. O existían pocas mujeres entre ellos, o les habían prohibido dejarse ver durante nuestra estancia". Forster: "Después del desayuno acompañé al capitán Cook y a varios oficiales a tierra, donde encontramos unos doscientos habitantes reunidos, entre los cuales había catorce o quince mujeres y muy pocos niños. Era imposible para nosotros adivinar la causa de esta desproporción en el número de los diferentes sexos".
} 
asesinatos), así como crear las condiciones para que su presencia fuera breve. En este contexto de "mostrar-dar-comerciar" / "invisibilizar-no dar-sustraer" puede ser leído el "sacrificio" de algunas mujeres:

“Entre ellos había una mujer, quien había llegado a bordo... y llevó a cabo un particular tráfico propio. Visitó a varios de los oficiales inferiores y, a continuación se dirigió a los marineros, emulando las famosas hazañas de Mesalina. Unos pocos trapos ingleses y algunas piezas de tela de Tahiti, fueron el botín que se llevó consigo, siendo recogida por un hombre en la parchada canoa, la que posiblemente era la única en la isla. Otra de las mujeres del país había visitado nuestro barco el día anterior y había sido igualmente desmedida en sus deleites. Quedó en duda entre nosotros, si debíamos admirar más su éxito entre una tripulación enfermiza, agotada por la larga prolongación de una dieta nociva, que su propio espíritu y temperamento insaciable" (relación de George Forster).

Este juego político rapanui, "cálculo salvaje" en los términos de Sahlins (2008), fue tanto o más impactante para los europeos que su cultura megalítica, así en las instrucciones reales dadas al conde de La Pérouse para cuando visitara Pascua eran:

“Dans sa relâche à l'isle d'Easter ou de Pâque, il s'assurera si l'espèce humaine s'y détruit, comme on a lieu de la présumer d'après les observations et le sentiment du capitaine Cook" (La Pérouse, Vol. I, p.26).

No obstante, la llegada de La Pérouse a la isla, el 9 abril de 1786, sitúa las cosas de otro modo:

“...como el hombre es, de entre todos los seres, aquel que más se habitúa a todas las situaciones, este pueblo me ha parecido menos desgraciado que al capitán Cook y al señor Forster. Ellos llegaron a esta isla después de un viaje largo y penoso, faltos de todo, enfermos de escorbuto y no encontraron ni agua, ni leña, ni cerdos; algunas gallinas, bananas y patatas, son muy pobres recursos en esas circunstancias. Sus relatos llevan el sello de esta situación. La nuestra era infinitamente mejor: los tripulantes gozaban de la más perfecta salud, habíamos tomado en Chile aquello que nos era necesario para varios meses y sólo queríamos de este pueblo la facultad de hacerles el bien. Les trajimos cabras, ovejas, cerdos; teníamos semillas de naranjo, de limonero, de algodón, de maíz y, en general, de todas las especies que podían ser aptas para su isla" (La Pérouse, Vol. II).

La gratuidad de La Pérouse tiene que ver con una dimensión colonial, se trataba de experimentar con la población local y sus territorios si era posible la reproducción de esos alimentos para las futuras colonias. Cook había dado semillas y animales a los habitantes de distintas islas, La Pérouse llevaba órdenes de ver sus resultados:

"Il s'informera si les bestiaux et les autres animaux et oiseaux vivans, que le capitaine Cook a dépose sur quelques unes de ces isles, y ont multiplié; quelles graines, quels légumes d'Europe y ont le mieux réussi, quelle méthode les insulaires ont practiquée pour les cultiver" (Vol.I, p. 26).

La imagen "alimentaria" que ofrecieron los rapanui a los extranjeros fue tal, que quizás generó las condiciones para que sus tierras y población quedaran fuera de los intereses coloniales europeos en el siglo XIX. La sentencia de Cook pesará a través de décadas: 
“Ninguna nación debe ambicionar el honor de haber descubierto esta isla, pues pocos sitios hay que tan mal se presten para el abastecimiento de buques. No hay fondeadero seguro, ni leña para combustible, ni agua dulce que merezca ser llevada a bordo. La naturaleza ha sido excesivamente parca en sus favores a este lugar, pues todo ha de ser obtenido a fuerza de trabajo; debe suponerse que los habitantes no cultivan más que lo que necesitan para sí mismos, y como son muy pocos en número, nada les sobra para abastecer a los visitantes extranjeros".

No obstante, en el siglo XIX, la demanda de mano de obra hizo de Pascua un lugar apto para el colonialismo más brutal, no de las potencias europeas sino de un lugar próximo: Perú. Entre 1862 y 1863, bajo el manto de contrato de trabajos, son esclavizados varios cientos de rapanui, siendo enviados a las guaneras y estancias del Perú. Más tarde una epidemia de viruela, traída por uno de los pocos sobrevivientes de las razias esclavista, diezmó a gran parte de su población. En 1864 llega a Pascua el primer misionero católico, el hermano Eugenio Eyraud de los SS.CC.

Los datos que proporciona Eyraud (1864) dan las primeras pistas del devenir colonial rapanui. Por un lado, la continuidad de la técnica del $u m u$, la perseverancia en la producción e ingesta del camote y el consumo de pollos y gallinas. Del mismo modo, el peso del kumara (camote) como medida de las relaciones y nexos sociales, en tanto "moneda" y como "pan". Informa, asimismo, respecto del nexo alimento-fiesta, y las ocasiones de congregación ritual (paina -a los antepasados- y areauti-danza y construcción-) como parte de un ciclo anual.

"Así es que las reuniones y las fiestas son continuas. Cuando terminan en un punto de la isla, comienzan en otro. El carácter de estas fiestas varía según la estación. En verano son los Paina que atraen a toda la población. Cada uno lleva su alimento para el tiempo de la fiesta, sobre todo para el último día, día del banquete. Todas estas raciones colocadas en hileras y cubiertas con ramos, constituyen el plato principal. Cuando se han hecho, según las reglas de la etiqueta, todas las evoluciones que se quieren, hasta que llega el último día se comen los camotes (Op.cit., p. 17)".

La carne de oveja aparecerá por primera vez como alimento, traído por el propio Eyraud: "En una fiesta agarraron mis ovejas, las asaron y se las comieron. Las ovejas asadas fueron cantadas no sé cuánto tiempo"19, ovejas que, posteriormente, como veremos, fueron incorporadas de manera masiva a la isla cuando la colonización y la explotación capitalista se instale de manera definitiva.

En 1888 se abrió una nueva etapa colonial para la sociedad isleña cuando Chile la incorpora como parte de su territorio en base a un "acuerdo de voluntades", firmado por el rey, los jefes rapanui y las autoridades chilenas. No obstante, el Estado chileno abandonó el proyecto de colonización para arrendar la Isla una Compañía ganadera en 1895 cuya mano de obra sería la misma comunidad. Se produce un pacto tripartito entre comunidad, Estado y Compañía, que tenía al menos dos lecturas: desde la Compañía los rapanui eran simples inquilinos, desde éstos eran soberanos al conservar el dominio sobre la totalidad de la tierra y ser dueños de buena parte de los

\footnotetext{
${ }^{19}$ Se refiere a los cantos de los areauti y las ovejas, las cuales obtuvo en Gambier: "Se embarcaron en la Suerte, cuyo navío depositó á los mangarevos en Gambier, donde estacionó tres días. El hermano Eugenio se proporcionó cinco carneros y varias púas de árboles con el objeto de aclimatarlos en la isla de Pascua" (Carta del padre Pacomio Olivier, 1864).
} 
animales (corderos: mamoe). La primera fue la Compañía de Merlet, que implementa la hacienda ganadera en Pascua, y luego, en 1903, la Compañía Explotadora de Isla de Pascua, de propiedad de los anglo-escoceses Williamson and Balfour. Así se desarrolla la producción de ovinos y con ella una relación empresarial y geo-política que expone las tierras de la isla a capitales extranjeros $\mathrm{y}$, a la vez, las controla administrativamente imponiendo las normativas del Estado.

En esta fase la evangelización católica, que ya había operado en manos de Eyraud, se re-establece con la particularidad que estará un largo tiempo en manos de pascuenses que habían sido llevado a Tahití por el Obispo de esa diócesis. Esta ritualidad católica será ejercida por algunos catequistas rapanui y tal vez este hecho religioso permitió la rearticulación de la reciprocidad a través del signo alimento y la reconstitución de una comunidad tensionada por la colonialización (los extranjeros "dueños" de la empresa ganadera) y la "chilenización" (los agentes del Estado). La historia oral y algunos documentos permiten decir que la apropiación sincrética de lo "católico" hizo posible la recomposición social amenazada por las fuerzas coloniales, al mismo tiempo que la propia iglesia operó en muchos casos como "defensora" de los derechos de los isleños ${ }^{20}$.

En esta fase se irán adosando nuevos alimentos bajo un modelo, lo que implicó no sólo "importaciones" de ganado, sino un tipo de propiedad, de producción, de "orden político" y simbólico en torno a éste. El nuevo signo-alimento de la carne roja, ya sea de oveja, de vacuno o cerdo incorporado al umu, propone otro giro a la gastropolítica isleña, pues formará parte de los conflictos entre imposición colonial y libre decurso de la cultura rapanui. El relato oral rapanui recuerda la entrada de los alimentos exógenos en tiempos de colonización, quién llevó los animales y cómo se reprodujeron, forma parte de una historia que Policarpo Toro, el primer agente del Estado chileno también conservó:

"Según las relaciones de los indígenas las primeras ovejas introducidas en Pascua fueron llevadas de Tahiti por un francés Mr. Bornier, que se hallaba ya establecido en la isla a principios de 1868, cuatro años después de haber llegado a la misma el primer misionero. Un nuevo misionero, el padre Gaspar, de la congregación de los SS.CC. llevó de Valparaíso a Pascua, poco después que Bornier, otra pequeña partida de ovejas.

A la opulenta señora chilena doña Isidora Goyenechea Cousiño se debieron en seguida los primeros animales vacunos y caballares introducidos en Pascua: a la vuelta de un viaje de placer o de salud, hecho a las islas de la Oceanía en un vapor de su propiedad, dicha señora dejó en la isla cuatro o seis vacas y un toro y una o dos yeguas y un potro, obsequio a los misioneros, quienes los aumentaron con otros llevados de Tahiti.

Por su parte el francés Bornier hizo un viaje a Tahiti, y concertado allí con un Mr. Brander, de origen inglés, llevó también a las islas de Pascua algunos animales vacunos y caballares que reproducir, y una cantidad de ropa, utensilios y otros objetos, en cambio de los cuales obtuvo de los indígenas, sin mayor formalidad, la cesión de diversas porciones de terreno" (1892, p. 199).

"Los referidos animales aumentados, como he dicho, con otros llevados de Tahiti en diversas ocasiones, se reprodujeron fácilmente. Los de Bornier formaron la base de los que hoy pertenecen a los dos hijos de su socio o habilitador Brander. Los de la Misión fueron vendidos por los padres a un francés de Tahiti, señor Salmon, i formaron la base de los comprados a éste por el Gobierno de Chile" (1892, p. 200) ${ }^{21}$.

\footnotetext{
${ }^{20}$ Es la tesis de Nelson Castro expuesta en su libro Rapa Nui. El diablo, Dios y la profetisa, Rapa Nui Press, 2006.

${ }^{21}$ Nótese que los "indígenas" "cedieran" parte de sus terrenos a cambio del ganado y otros objetos.
} 
Lo que Toro registra con tanto detalle es la nueva realidad de la isla, así como el origen y protagonismo de los animales que serán explotados. No obstante, persiste el consumo de los productos endémicos y sus recetas, y el mismo Toro destaca la fuerza del umu en el intercambio matrimonial:

"Cuando dos tratan de casarse, deben comenzar por obtener el permiso de sus respectivos padres adoptivos i naturales, de ambos sexos. Si éstos consienten, se dirijen todos a manifestarlo así al Kin, i éste ordena al que hace de sacerdote que lo ponga todo por escrito i que anuncie el próximo día del matrimonio, en un papel fijado en uno de los palos de bandera plantado en Hangaroa. El anuncio tiene por objeto dar lugar a los preparativos de la fiesta, a la cual todos debe concurrir llevando ovejas, gallinas, camotes, taros, pescados i mariscos etc., destinado todo a ser cocido en un hoyo con piedras calentadas i comido en la fiesta matrimonial" (1892, p. 200).

Se mantiene aquí la lógica de los dones que circulan en beneficio de la reproducción comunitaria y se aprecia la inclusión de la carne de cordero en el umu. La oveja, al ser incorporada a los alimentos "fundacionales", aparece como signo del intercambio y de la reciprocidad. Por otro lado, el testimonio ya citado da cuenta que los delitos fueron multados con el pago en:

“... dinero o especies, camotes, plátanos, gallinas etc., todo lo cual se reparte de tiempo en tiempo entre el Kin, los consejeros o ministros i los pacos" (1892, p. 204).

Aunque el dinero está presente, los alimentos siguen siendo medida de cambio y por tanto su sentido de "don" no se ha perdido. Por ello, la colonización no afecta, conjeturamos, al núcleo del sistema alimentario, sino que lo expande con la rapanuización de lo que se adopta. La aparición de nuevas tecnologías, por ejemplo, las ollas, introduce la oposición cocción al vapor-umu/ cocción al agua- cazuela que producirá más adelante una nueva: cazuela rapanui/cazuela chilena que especificará diferencias que la gastropolítica convertirá en una distinción que construye el orden cultural propio y el de los "otros".

Pero, donde la gastropolítica rapanui adquiere fuerza y relee a su sociedad es en "la guerra de las comidas" (Montecino, 2009). Se trata de la "Rebelión de Angata"22 que, analizada desde una perspectiva de género y de la función negociadora de la cocina, otorga un nuevo rumbo a las tensiones políticas entre isleños y colonizadores. Los cuarenta años posteriores a la anexión fueron tiempos conflictivos y duros, pues desde la vista de los rapanui el pacto con Chile tuvo como objetivo mejorar su calidad de vida, no obstante la realidad demostró lo contrario:

\footnotetext{
${ }^{22}$ Entre quienes se han referido a este suceso están Castro (1996); Fischer, H. (2001); Fischer, S. (2005); McCall (1996) y Seelenfreund et. al. (2004).
} 
“No menos importante es que Rapa Nui era independiente, tenía rey, su propia bandera y un Consejo de ancianos o Jefes, esto es fácil comprobar en el acuerdo de voluntades entre los Jefes o Ancianos rapanui en representación del pueblo pascuense y Policarpo Toro Hurtado en nombre del gobierno de Chile el 9 de septiembre de 1888 en que el rey Atamu Tekena de Rapa Nui, entregara la soberanía de la Isla de Pascua para el gobierno de Chile y al mismo tiempo se reserva el derecho de los pascuenses sobre sus tierras y la investidura de los Jefes o Ancianos. Por otra parte Policarpo Toro Hurtado Capitán de Corbeta de Marina de Chile, ofrece a cambio de dicha soberanía, progreso, protección, respeto, educación y otros, en que Chile no cumplió nada sino fuimos esclavizados" (en Hotus y otros 1988, p. 293).

Los rapanui comprenden el pacto como un vínculo político que suponía las nociones de reciprocidad y de intercambio, no obstante los colonizadores tenían la idea de apropiación del territorio insular como sustrato del deseo capitalista ${ }^{23}$. Por otro lado, la implantación de una economía de estancia ganadera, con el consecuente disciplinamiento de los isleños y el confinamiento en sus propias tierras, provocó las tensiones que se resolvieron mediante la gastropolítica: resolver el nudo del poder y control del signo-alimento- oveja por parte de los colonizadores:

“Debían cavar pozos profundos, hacer pircas de piedras para dividir los campos....sin alimentos y en noches de luna debían prolongar el trabajo hasta media noche...muchos recién nacidos murieron de hambre y falta de atención...Todos ellos, después de su trabajo, en las noches y cansados debían pescar en la orilla para recién en esa hora comer algo...

Todos estos trabajadores eran obligados a trabajar como esclavos y si se negaban, eran azotados y sus plantaciones eran quemadas y quitados sus animales, como: caballos, vacas y otros, por el colonizador" (Op.cit., p. 296).

Se trata de la ruptura del intercambio de trabajo por comida, de la destrucción de las fuentes dealimentación propias (cultivos y ganado) y del goce unilateral delos animales. Este quiebre impide la circulación de lo que nutre a los vivos y a los antepasados $\mathrm{y}$, al mismo, tiempo a la comunidad rapanui. La sucesión de administradores que ejercieron el poder con prepotencia (Cooper y Sánchez Manterota), y con medidas cada vez más coercitivas, tuvo como respuesta la "revuelta" liderada por Angata.

Asesinado el rey Riroroko en el continente, se produce asimismo un quiebre en las jefaturas masculinas, asumiendo por primera vez una mujer ${ }^{24}$ : María Angata Veri Tahi a Pengo Hare Kohou, cuyo discurso ha sido calificado de milenarista ${ }^{25}$, y que nosotros proponemos arranca y relee los sentidos propios de la gastropolítica rapanui. Angata concitó a recuperar el alimento y a restituir el orden subvertido por los colonizadores. El eje de su impugnación fue recuperar los animales, tenidos

\footnotetext{
${ }^{23}$ Ese "deseo" llevó a los comerciantes franceses, primero, y luego ingleses a maniobras por la cesión de los derechos sobre las tierras rapanui, lo que fracasó por la inscripción de la "isla" como "tierras fiscales" en 1933 por el Estado chileno. Los isleños no permanecieron pasivos ante esas imposiciones y cambios. La resistencia tomó diversas maneras, una de ellas fue la eliminación comunitaria de Bornier y de Bautista Cousin (Foerster 2012).

${ }^{24}$ No tenemos datos documentales ni orales de que hubiera habido antes una "ariki" en Pascua. Sherry Ortner (1989) encontró en Hawai una fisura al poder masculino una vez que la colonización y otros conflictos endógenos llevaron a que una mujer tomara la jefatura.

${ }^{25}$ Consúltese la obra de Nelson Castro, El diablo, Dios y la profetisa. Evangelización y milenarismo en Rapa Nui 18661914, Rapanui Press, Rapa Nui 2006.
} 
como propios, "secuestrados" por la Compañía Explotadora. La primera estrategia fue la de su sustracción -tipificada como "robo" por parte de los colonizadores- para un consumo pantagruélico, goloso y ritual. Esto desató "la guerra de las comidas" . Catherine Routledge autora de The Mystery of Easter Island ${ }^{26}$, testigo de los sucesos, devela fases de la rebelión que iluminan el argumento gastropolítico:

"El 30 de junio, cuando todavía estábamos en la casa del administrador comenzó a desarrollarse algo que hizo que las próximas 5 semanas se transformaran en una ópera cómica, una obra que, sin embargo, hizo que ese tiempo fuera el de más ansiedad en la historia de la Expedición. Ese día, una anciana semiparalítica llamada Angata llegó a la casa del Administrador acompañada de dos hombres y le informó que Dios le había enviado un sueño de acuerdo al que M. Merlet, el Presidente de la Compañía "ya no lo era" y que la isla pertenecía a los kanakas, los que debían apoderarse del ganado y tener una fiesta al día siguiente" (1919, pp. 141 - 142).

Esta recuperación de la "tradición" a través del comensalismo se aprecia documentalmente: Daniel Antonio, uno de los líderes que acompaña a Angata, firmó esta carta dirigida al administrador Edmunds el 30 de junio de 1914:
“...le declaramos nosotros, que es la lengua que hablamos hoy día, que deseamos llevar todos los animales al campamento y todas nuestras posesiones que están en sus manos ahora, ya que usted sabe que todos los animales y tierra del campamento nos pertenecen; nuestro Obispo Tepano ${ }^{27}$ nos las dio en un principio. Nos la dio en verdad y justicia. Hay otra cosa, los pocos animales que están al frente suyo, son para que Ud. coma. Todavía hay otra cosa, mañana vamos a ir al campamento a buscar animales para un banquete. Dios está con nosotros, su verdad y su justicia. Existe otro asunto más, no recibimos al que le dio los animales a Merlet, tampoco al que le dio las tierras a Merlet porque es un gran robo. Nos quitaron esa posesión a nosotros y no dieron nada a cambio de las tierras, ni dinero ni bienes ni nada. Nunca se les dieron a ellos. Ahora sabe lo que tiene que saber. Su amigo "Daniel Antonio" (1919, p. 142).

El fundamento religioso del movimiento de Angata queda esbozado: tras la tierra y los animales, fuentes esenciales del alimento, está lo divino y el quiebre de la lógica de los intercambios es claro. La palabra "robo" designa la ruptura de una cierta gastropolítica: la de las equivalencias alimenticias. Los rapanui saben que los colonizadores tasan y valoran las tierras, el dinero, los bienes y entienden que, ni siquiera bajo esa lógica, están siendo compensados.

La lideresa Angata soñó nuevamente con Dios quien le dijo "estaba muy complacido de que los kanakas se hubiesen comido la carne y que debían comer más aún" (1919, p. 143). La revancha glotona ante el hambre y la pérdida de los antiguos modos, reestablecen la comunidad rapanui ante sí misma y ante lo divino. En medio de este tinglado rebelde se unirán matrimonialmente cinco parejas jóvenes, sin la mediación "oficial" del administrador, pero sí de forma "solemne" en la iglesia. De este modo, re-apropiación de la iglesia, de los alimentos y recuperación de los rituales festivos serán el soporte de Angata y de sus seguidores. La atmósfera de la rebelión puede atisbarse, en parte, por el testimonio de Routledge:

\footnotetext{
${ }^{26}$ La traducción que usamos fue realizada por Camila Laureani y su equipo, y se encuentra en el Archivo Nacional.

${ }^{27}$ De acuerdo a Bienvenido Estella, el Obispo Tepano Jaussen, Vicario Apostólico de Tahiti, estuvo en Pascua en 1868.
} 
"Iré a visitar a la anciana... El lugar era un perfecto matadero, mitades de animales colgaban de los árboles y los cueros habían sido separados para que se secaran... La profetisa estaba junto a un grupo afuera de la casa del sacerdote que era su hijo político. Era una anciana de pelo cano y ojos expresivos, una personalidad diferente y atractiva. Llevaba al cuello una especie de medalla religiosa, creo que era una cruz roja sobre un fondo blanco y su hija, que la apoyaba, llevaba un pequeño retrato del Salvador con un marco Oxford...Yo le había llevado un obsequio y comencé agradeciéndole las aves. Rehusó todo tipo de retribución diciendo "la comida la envía Dios, no deseo dinero alguno" y procedió a ofrecerme un poco de carne..." (1919, pp. 144-145).

Es interesante el género de esta conversación: dos mujeres con poder, una en el polo de la escritura y el intelecto y la otra en el de la rebelión divina son los "símbolos" de un diálogo gastropolítico casi imposible. Los colonizadores le piden a Routledge que "medie" con Angata, es decir las negociaciones toman en este momento un claro sentido de género y etnicidad, asumiendo ambos bandos el rol político femenino. El rechazo de Angata a los presentes de la inglesa pone de manifiesto que la carne es la moneda y no el dinero, y será Dios mismo quien opere en esa metáfora y en su consecuencia: una lógica difícil para la inglesa:

"Dios no dejará nunca que se mate o hiera a los kanakas... Angata dijo que "rezaría" por mí, agregando con condescendencia que si alguna vez tenía "gallinas o papas" yo sería la primera en compartirlas" (1919, p. 145).

El discurso gastropolítico de Angata se ancla en la ideología de los dones sincretizada con elementos cristianos: es superior quien da (rezos) y comparte (comidas), más al interior de el "perdón" de quienes nos ofenden, y en el compartir entre hermanos. Se explicita así un sistema de prestaciones, que va desde lo divino a lo humano y entre éstos y los antepasados en un movimiento que iguala y desiguala permanentemente. Pero, pensamos que asimismo la memoria de un Dios Make Make, que hacía no demasiado tiempo clamaba y pedía carne humana para saciarse, debió haber estado en el recuerdo de la vieja Angata y sin duda, en el de los colonizadores. A los colonizadores no les quedó más que asumir, en esos momentos críticos, la lógica de los alimentos como signos vicarios del "pago" y de su consecuente cadena de reciprocidad:

"... El "sacerdote" que se encontraba con ellos y que llevaba un retrato de la Virgen leyó algo que presumimos era una plegaria. Al finalizar ésta los demás se persignaron. Luego nos comunicó los saludos de Angata.... Los hombre extraían de sus alforjas huevos, papas y alrededor de una docena de gallinas. No nos pareció grata esta posición pero pareció mejor aceptar los obsequios en vista que ninguna de estas cosas eran robadas y le dimos a cambio parte de nuestra comida" (1919, p. 146).

La llegada de la Baquedano, buque escuela de la Armada chilena, apaciguó la revuelta y aunque se realizó una investigación sumaria, no hubo represalias contra la lideresa. Angata murió seis meses después y su funeral se celebró con un festín de chanchos. Sin duda el umu en el cual se cocinaron delata que la rebelión no fue en vano. Del mismo modo tuvo sus frutos en los derechos que poco a poco fueron adquiriendo los rapanui sobre los animales de la Compañía. Asimismo el "robo" de los animales de la 
estancia irá adquiriendo con el tiempo un evidente sentido gastropolítico, una señal y una constante advertencia de que los isleños persistieron en sus nociones del alimento como un "bien" anclado en una densa cadena de retribuciones.

\section{Rituales culinarios y etnopolítica}

Ya en la primera mitad del siglo XX se cristalizará en Isla de Pascua un modo de organización social: la explotación ganadera, la dependencia de la Armada de Chile, la Iglesia católica -instalada con los capuchinos- y la comunidad serán sus actores centrales. Los conflictos y tensiones persistieron, así como la resistencia rapanui y sus demandas a la Compañía Explotadora, siempre signadas por la marca alimenticia:

"Consiguieron que se instalara un comedor con mesa, plato, ollas y servicios, terminando así con los medios tambores en que se cocinaba anteriormente, obligados a comer en cualquier lugar, incluso en el suelo lleno de moscas" (Hotus, Consejo de Jefes Rapa Nui, 1988, p. 364).

Por cierto, la memoria de muchos isleños ve de modo positivo ese período: la aparición de una pulpería -de propiedad de la Compañía- trajo consigo nuevos productos como azúcar, tarros de conservas, harina, y ollas, además de vestuario. De acuerdo a los datos documentales la reciprocidad culinaria y los alimentos como regalos se mantuvieron, aunque rearticulados a nivel de las familias que se prodigaban alimentos de manera libre ${ }^{28}$. La lógica del "individuo" y de la "propiedad privada" de los medios de producción y reproducción ${ }^{29}$ no habían permeado a los isleños. Los funerales se celebraban como antiguamente, de acuerdo a Bienvenido Estella:

"...todos llevan sus presentes; pues nadie quería ser menos: pollos, pavos, corderos, camotes y plátanos; todo eso se veía amontonado, y pronto para meterlo en el Umu (curanto)... Sobre ellas (piedras candentes) colocan los comestibles en crudo, o sea: pollos, pavos, corderos, carne de vacuno, peces, camote, plátanos, etc.;...Pasadas seis horas, se calcula que todo está bien cocido; pero es quien hace de cocinero o dirige el curanto quien dará la señal del kai-kai o comida. No importa la hora, para los pascuenses nunca es deshora para comer; cuando hay se come" (Op.cit., pp. 20-21).

Corderos y vacunos se han consolidado como alimentos de las comidas rituales, dialogando al interior del umu con los alimentos ancestrales. Para el sacerdote esta forma de duelo era "bárbara" (los funerales implicaron varios festines), e instó a cambios que, al parecer, sólo fueron de forma, como se percibe de la cita. Los corderos y bueyes para los umu colectivos debían obtenerse de la Compañía Explotadora (CEDIP) contra prestación en trabajo ${ }^{30}$. Hay que sumar a las celebraciones propias, las que emergieron en el proceso de "chilenización", ampliándose el ciclo "festivo", de acuerdo al subdelegado Recabarren, en 1926:

\footnotetext{
${ }^{28}$ Hoy día se observa también la costumbre de alimentar a quien no tiene o al que pasa junto a quien esté comiendo.

${ }^{29}$ Nos referimos al concepto de Meillaseux (1977), quien define los medios de reproducción como las semillas y las mujeres.

${ }^{30}$ De acuerdo al sacerdote debido a los muchos rituales, los pascuenses estaban todo el tiempo en "deuda" con la Compañía, consigna que en los funerales se consumían de 10 a 30 corderos, 2 bueyes y una enorme cantidad de camote, ñame y pollos.
} 
“33.-En celebración del 21 de Mayo hubo saludos de 21 cañonazos en memoria del Gran Capitán, Don Arturo Prat; hubieron carreras de a caballos, tiro al Blanco y otras diversiones, todos con permisos de 10\$, también se mataron 2 novillos y toda la jente quedó sumamente contenta.

34.- Fiesta Nacional 18 de Setiembre de 1926.-Con motivo de esta gran fiesta de nuestra independencia de Chile, desde las 6 A.M. a 6 A.M. hubieron fiestas, carreras de a caballo y otros juegos más, también se mataron dos novillos y se distribuyó a todos los habitantes, quedaron todos mui contentos, cerrándose las fiestas con 21 Cañonazos a las 6 P.M.

35.- Fiesta de Pascua y Año Nuevo.-La jente mui entusiasta con estas fiestas. Banderas faltan y otros elementos más para estas fiestas, hubo carreras de a caballo, tiro al blanco y otros juegos más.

24.- Entrega de Corderos de la Cía. para esta Subdelegación. Mensualmente esta Cía. me entrega cincuenta corderos para el gasto de la Subdelegación y para el consumo de los enfermos Leprosos, el sobrante para los pobres y algunos se venden para comprar mercaderías y de Luz, etc."

La sociedad rapanui, ante los códigos impuestos -es la hipótesis que tenemos- hará un camino en el que la ritualización alimentaria tomará un nuevo giro. La etnopolítica frente a la "nación" chilena encontrará en la gastropolítica una clave para construir su diferencia cultural. Si antes la fiesta y el banquete funcionaron como bisagras sociales, en un escenario donde emergieron nuevas medidas de valor de las cosas y de los seres humanos, la carga ceremonial de los umu en las distintas fiestas colectivas asumirá lo "propio", reproduciendo la reciprocidad entre las familias y entre ellas y las divinidades (con un panteón católico rapanuizado), así como con los antepasados. Fuera de este circuito se expande la moneda como equivalencia y los pascuenses aprenderán a manejar sus vaivenes. Relegados al poblado de Hangaroa y con un acceso limitado a tierras, hilvanaron su "etnicidad" en medio de la chilenización, la proletarización (ser trabajadores de la Compañía) y la evangelización. Asimismo, el mestizaje tuvo su impronta tahitiana, chilena y europea, incidiendo en la refundación de la que hablamos. Estos cambios implicaron el arribo de nuevos alimentos, valorados desde otras ideologías nutricionales y técnicas distintas de producción y consumo. Se recreó entonces el sistema alimentario rapanui, pero al mismo tiempo se profundizaron sus viejas estructuras.

Será sólo en la década del 60 cuando los rapanui, luego de constantes luchas, obtengan la ciudadanía chilena -derecho a voto y a representación política en el Estado Chileno $^{31}$. Esta época coincide con la llegada de los aviones y por tanto se inaugura una conectividad y una comunicación cada vez más expédita con el "conti" (Chile), se transforma asimismo la Compañía quien pasa a manos del Estado.

Este proceso significarála entrada a una "interculturalidad" distinta en la cual lo rapanui también se reconfigurará. En el plano de la alimentación trajo consigo variedades cada vez más amplias de productos, semillas, plantas y utensilios domésticos, así como la llegada de "turistas", visitantes y "continentales" que comienzan a formar matrimonios mixtos. Junto a estos cambios, se aprecia la consolidación del ceremonial festivo que toma de manera evidente los hitos católicos como parte de un ciclo

\footnotetext{
${ }^{31}$ Ver Grifferos (1997 y 2000).
} 
indispensable para verificar la comunidad rapanui. La gastropolítica define hoy día un ciclo anual de fiestas colectivas en torno a una seguidilla de "umu religiosos" en los cuales se escenifican las estructuras contemporáneas de prestigio rapanui, expresadas nítidamente en la repartición de la comida. Antes de esta, el ritual de apertura del umu es realizado con la presencia de un sacerdote y con oraciones que tienen como fin -de acuerdo a los isleños- agradecer el alimento que brindan los antepasados(as), del mismo modo que invitarles a comer (se dice que el vapor que sale del horno de tierra es su alimento).Las enormes bandejas de carnes cocidas que salen del umu de quien lo "ofrece", serán distribuidas primero, a las personas de importancia, de la isla o del exterior $^{32}$. Algunos rapanui sostienen que esa jerarquía obedece al mana que portan. Una vez que ellas han recibido sus raciones de cerdo, vacuno, cordero, tubérculos, platános y poe, se procede a la "donación" para el resto (adultos, ancianos y niños). Se trata casi siempre de más de 300 personas que esperan ansiosas su parte en el banquete y entre las cuales no se hace diferencia entre isleños, turistas o visitantes, todos/as son objeto de la prodigalidad del oferente.

Ser parte del conjunto de familias que participan en los umu religiosos implica una desafiante responsabilidad económica y laboral:

"En todas las festividades religiosas, vale decir católicas, se hace curanto, para San Pedro, San Pablo, en fin todos los santos. Hay familias especiales, puntuales, que tienen que hacerlo, por ejemplo para la fiesta de San Miguel, es como que adoptan un patrono porque el papá de ellos se llamaba Juan, entonces él tiene hijos y nietos que llevan el nombre Miguel, Juan Bautista, entonces por lo menos en esa familia, se hace el curanto para Miguel Arcángel. La virgen del Carmen también, las familias que lo hacen son bueno la familia de Tahai son los Haoa, la tía Lucía Riroroco, es esposa de uno de los hijos de Juan Haoa, este viejito ya falleció, pero estos hijos continúan haciendo el curanto, entonces es como que se va heredando y los hijos continúan haciendo, si no, se pierde esa parte" (Angie Pont).

El ciclo ritual de los umu contemporáneos se despliega de este modo: Marzo-Abril, Semana Santa, efectuado por la familia Calderón Teao. Antes lo hacía el padre de Noemí Pakarati, quien recuerda:

“Semana Santa mi papá hacía antes, un primo de mi papá haciendo y como era primo entonces mi papá ayudaba a hacer... se hacía harto pescado, crudo y cocido, plátano; de toda clase de fruta, zapallo, sandía, taro, de todo clase; y pescados atún, langostas. Lo hacía al lado de la iglesia... y toda la gente llega y se sienta con todos sus hijos, esa familia con todos sus hijos sentada. Se sale de la misa y se sienta y se pone a comer tranquilamente, y regala zapallo, sandia, plátano, de toda clase de plátano, de toda clase de taro,así grandes, pescado crudo, cocido, ahumado también se regala, iprecioso! para la semana santa".

En Mayo, Pentecostés 33 , 3 de Mayo, Cruz de Mayo (ofrecido por la familia ArakiPakomio); 7 de Junio, Sagrado Corazón de Jesú por la familia Ika-Paoa; 29 de Junio, San Pedro a cargo de los pescadores, quienes aportan los peces y el trabajo; 16 de julio, Virgen del Carmen, ofrecido por dos familias: Ika Nahoe y la familia Teao, quien lo

\footnotetext{
${ }^{32}$ En ocasiones hemos observado visitas de Tahiti, así como parientes que viven en el continente.

${ }^{33}$ Se celebra 50 días después de la Pascua de Resurrección.
} 
dejó a Sebastián Pakarati Atan, hoy es representado por Silvia Pakarati; 22 de agosto, Sagrado Corazón de María a cargo de la familia Paté Tuki; 29 de septiembre, San Miguel Arcángel, brindado por la familia Haoa Pakomio; 8 de diciembre, Inmaculada Concepción, realizado por Magdalena Laharoa; 25 de diciembre, Navidad, ofrecido por la familia Nahoe Araki.

Este ciclo posee los ecos de los condumios festivos del pasado en el hoy, encabalgados con fechas católicas, pero con el sentido de reproducir a la comunidad a través de las ofrendas alimenticias de las familias y con el significado gastropolìtico de la reciprocidad. Esta comunidad se expande a los(as) rapanui residentes en el continente: cada septiembre, en Santiago, en el Templo Votivo de Maipú, se efectúa una misa y un gran umu. El congregacionalismo y la distinción a través del don alimenticio y del prestigio de las familias que lo llevan a cabo se mantienen a pesar de la lejanía. Muñoz (2007) registró tres grandes umu en la capital. El del Templo Votivo de Maipú, se ofrece hace 30 años y aunque relacionado a la anexión de la isla a Chile, cobra sus visajes comunitarios con el eje devocional del Cristo Rapa Nui, los gastos festivos y la comparecencia de una gran cantidad de familias.

Parte de la etnopolítica de hoy día se observa en la gastropolítica de los umu religiosos, en la medida en que las negociaciones de la identidad pasan por la cocina. La oposición umu turístico/umu religioso da cuenta de ello. El primero se realiza ad-hoc en algunos restaurantes, como parte del "etnoturismo", pero sin ninguna de las ceremonias religiosas de los que pertenecen al ciclo. Al interior de las tensiones con el Estado nacional, el mercado, el turismo y los efectos de la globalización, la cadena de umus religiosos sitúa y resitúa constantemente a una comunidad que fija reglas paralelas a las de la individuación, una política de la reciprocidad a través del alimento, una política de la identidad como "pacto" entre familias.

Es interesante señalar que los umu que se hacían el 18 de septiembre y el 21 de mayo, gestas nacionales chilenas por excelencia, se han dejado de realizar. Sin embargo, hay un umu no religioso, asociado al etnoturismo que se efectúa en la Semana Rapanui o Tapati, en febrero, que se cocina en medio de los juegos y competencias -revival de las ritualidades del pasado precolonial-. Este umu ocupa un lugar relevante, pero sus alimentos son financiados por el municipio y el trabajo no se verifica en las familias organizadas para tal fin, sino en gente diversa que coopera. La vida contemporánea, cercada por diversos influjos entre los cuales las políticas estatales, el turismo y el mercado resultan evidentes, junto a una conectividad inédita con Chile y el resto del mundo, plantean a la sociedad rapanui un desafío ligado a sus políticas de la identidad. Dentro de este desafío, la mantención de la idea del alimento como don resulta crucial, pues hace posible el decurso de una práctica que se verifica en lo íntimo y en lo común, en la comida cotidiana y en la festiva. Pervive aún la noción de que el alimento debe prodigarse a todos, que no se puede privar a nadie de él, y asimismo se rearticula de manera permanente la regla de alimentar a los "espíritus". La diferencia entre el umu turístico y el religioso pone de manifiesto la gastropolítica, así como el que la "cazuela rapanui", la kokoma o vísceras crudas, los pescados al tunuahi (a la piedra) comidos con la mano, el mautini y el olloy raque raque (suerte de 
postres con plátano y zapallo el primero, de harina el segundo) constituyan parte del sistema culinario rapanui que se ofrece en los restaurantes y hoteles (en ellos sólo algunas recetas rapanui conviven con la cocina "internacional"). Lo culinario "local" y lo "global" no dialogan en este caso, dibujando la comunidad una línea divisoria entre el alimento del circuito del mercado y el alimento del circuito de su sociedad.

Habrá que observar en el futuro si esa gastropolítica del umu y de otros platos emblemáticos rapanui no sucumben. Hasta el momento los isleños controlan el turismo ya sea a gran o pequeña escala, y los procesos locales son evidentes -sobre todo porque los propios rapanui se desplazan constantemente al "conti" (Chile), pero también mucho más lejos de sus fronteras e incorporan modelos turísticos de otros sitios. Esta realidad, por cierto propone constantes mutaciones que redundan en una discusión sobre la tradición, revivida, recreada, cambiante y no esencial, aunque lo que se "venda" como imaginario sea un producto para el visitante ávido de lo "otro". Sabemos que las identidades culinarias que surgen como formas locales en que la globalización alimentaria se expresa, arrojan una serie de fenómenos gastropolíticos relacionados con la competencia en el mercado del consumo de lo "auténtico", lo "originario", lo "propio". Lo local retoma los símbolos de lo nacional y lo regional para que los alimentos sean capaces de convertirse en mensajes claros de las particularidades de una determinada nación. Sin embargo, en el caso que hemos tratado en este artículo, hipotetizamos que la comunidad rapanui rearticulará constantemente sus sentidos a través de los productos alimenticios y técnicas que han sido caros a su dieta en el devenir de su historia, y del mismo modo negociará su derecho a la diferencia, colocando la gastropolítica como un conjunto de rituales de resistencia y expansión identitaria en la reproducción y cambio de su sociedad.

\section{Bibliografía}

Appadurai, A., "Gastro-politics in Hindu South Asia", en American Ethnologist 8, 1981, (3).

Bataille-Bengugui,M.C., "L'ordinairie et l'exception dans l'alimentation au rouyaume de Tonga, Polynésie occidentale", en Cuisines, Reflets des sociétés. Editions Sépiamusé de l'Homme, París,1996.

Behrens, C. F., Histoire de L'Expédition de Trois Vaisseaux, envoyés par la Compagnie des Indes Occidentales des Provinces-Unies aux Terres Australes, en MDCCXXI, par Monsieur de B... A La Haye, Aux dépens de la Compagnie MDCCXXXIX , 1739, Vol. 2.

Bourdieu, P., La distinción. Criterio y bases sociales del gusto, Taurus, Madrid, 2002.

Campbell, R., La herencia musical de Rapanui, Editorial Andrés Bello, Santiago, 1971.

Candau, J., Antropología de la memoria, Ediciones Nueva Visión, Buenos Aires, 2006.

Castro, N., Rapa Nui. El diablo, Dios y la Profetisa. Evangelización y milenarismo en Rapa Nui, 1864-1914, Rapa Nui Press, Rapa Nui, 2006. 
Contreras, J., "El patrimonio alimentario en el área mediterránea", en Patrimonio gastronómico y turismo cultural en el Mediterráneo, Jordi Tresseras y F.Xavier Medina (eds.), Ibertur, 2008.

Cook, J. Viaje hacia el polo sur y alrededor del mundo, Espasa Calpe, Madrid, 1938, 3 vol.

Diccionario Práctico Rapanui-Castellano (editado por Alberto Hotus s.f.).

Doughman, R., "La chipa y la soja: pugna gastropolítica en la frontera agraria del Paraguay Oriental" en Base. Investigación Social. Desarrollo Rural y soberanía alimentaria, 2010.

Englert, S., La Tierra de Hotu Matu'a. Historia, Etnología y Lengua de la Isla de Pascua. Imprenta y Editorial San Francisco, Santiago 2010.

Estella, P., Bienvenido de OFM, Cap., Los misterios de Isla de Pascua, Imprenta Cervantes, Santiago, 1920.

Mis viajes a Pascua, Santiago, Imprenta Cervantes, Santiago 1921.

Fajreldin, V., La medicina herbolaria en Isla de Pascua. Acercamiento antropológico a la cultura médica contemporánea Rapanui (ms). Memoria para optar al Título de Antropóloga, Universidad de Chile.

Fischer, H., Sombras sobre Rapanui, Lom, Santiago, 2001.

Fischer, S. R., The Turbulent History of Easter Island, Reaktion Books, Londres, 2005.

Fischler, C., El (h)omnívoro. El gusto, la cocina y el cuerpo. Random House Mondadori, Madrid, 1995.

Forster, G., A voyage round the world in his Britannis Majesty's sloop, Resolution, commanded by Capt. James Cook, during the years 1772, 3, 4 and 5 / by Georg Forster, London, printed for F. White, J. Robson, P. Elmsly; and Robinson, 1777, 2 vol.

Foerster, R., "Bautista Cousin, su muerte violenta y los principios de autoridad en Rapa Nui (1914-1930)", en Revista de Historia, 2012.

Fuentes, J., Diccionario y gramática de la lengua de la Isla de Pascua, Editorial Andrés Bello, Santiago, 1960.

Grifferos A., A. M., "La otra cara del paraíso. Comunidad, tradición y colonialismo en Rapa Nui, 1864-1964", Tesis de Licenciatura de Historia, Universidad de Valparaíso, 1997. 
“Entre palos y piedra. La reformulación de la etnicidad en Rapanui. Isla de Pascua 1966", en Estudios Atacameños, N¹9, 2000, pp. 121 - 133.

Hotus, A. y otros (Consejo de Ancianos) Te Mau Hatu o Rapa Nui, Editorial Remisión, Santiago, 1988.

edición), 2007.

Los soberanos de Rapa Nui. Te Mau Hatu o Rapa Nui (segunda

Huke, P., Mata Tu'u Hotu Iti, Editorial Tiempo Nuevo, Santiago, 1995.

La Pérouse, J. F. (1786) Voyage de La Pérouse autour du monde, publié conformément au décret du 22 avril 1791, et rédigé par M.L.A. Milet-Mureau, Général de brigade dans le corps du Génie, Directeur des Fortifications, ex Constituant, Membre de plusieurs Sociétés littéraires de Paris,1786, Vol. 4.

McCall, G., "El pasado en el presente de Rapanui (Isla de Pascua)", en Culturas de Chile. Etnografía. Sociedades Indígenas contemporáneas y su ideología, Editorial Andrés Bello, Santiago, 1996, pp. 17 - 46.

Rapanui. Tradición y sobrevivencia en la Isla de Pascua. Easter Island Foundation, California, 1998.

Meillaseux, C., Mujeres, graneros y capitales, Siglo XXI, México, 1977.

Mellén Blanco, F., Manuscritos y Documentos Españoles para la Historia de la isla de Pascua: La Expedición del Capitán D. Felipe González de Haedo a la isla de David, Colección Biblioteca CEHOPU, Cedes, Madrid, 1986.

Métraux, A., Ethnology of Easter Island, Bernice P. Bishop Museum, (Bulletin 160), Honolulu, 1940.

La Isla de Pascua, FEC, México, 1950.

Montecino, S., Fuegos, Hornos y donaciones. Alimentación y cultura en Rapanui, Editorial Catalonia, FIA-Universidad de Chile, 2009.

Ortner, S., Gender Hegemonies, University Minsessota Press, 1989.

Poulain, J.P., Sociologies de l'alimentation. Presses Universitaires de France, París, 2002.

Recabarren, C., "Manuscritos", en Archivo Nacional, Intendencia de Valparaíso, 1926-1930.

Roggeween, J., "Relación anónima”, en Alexandre Dalrymple, Voyages in the South Pacific Ocean, 1770-1771, Vol. 2. 
Routledge, C., The Mystery of Easter Island, Sifton, Praed \& Co. Ltd., London, 1919.

Sahlins, M., Islas de historia, Gedisa, Barcelona, 2008.

Seelenfreund, A.; Grifferos, A. ; Hucke, P.; Ramírez, J. M., "El Pueblo Rapanui", en José Bengoa (Comp.) La memoria olvidada. Historia de los pueblos indígenas de Chile, Cuadernos Bicentenario, Santiago, 2004.

Toro, P., "Isla de Pascua. Santiago, noviembre 15 de 1892", en Memoria de Relaciones Esteriores, Culto I Colonización, 1892, pp. 187-216 (fueron también publicadas por el diario El Mercurio de Valparaíso, en noviembre de 1916).

Weinsmantel, M., Alimentación, género y pobreza en los Andes Ecuatorianos, Abya-Yala, Quito, 1994. 